\title{
NET RADIATION WITHIN A CANOPY OF SWEET CORN DURING DROUGHT
}

\author{
R.B. CAMPBELL, D.C. REICOSKY and C.W. DOTY \\ Coastal Plains Soil and Water Conservation Research Center, Southern Region, USDA- \\ SEA/AR, Florence, SC 29502 (U.S.A.)
}

(Received January 22, 1979; revised and accepted April 16, 1980)

\begin{abstract}
Campbell, R.B., Reicosky, D.C. and Doty, C.W., 1981. Net radiation within a canopy of sweet corn during drought. Agric. Meteorol., 23: 143-150.
\end{abstract}

Net radiation above and within a canopy of sweet corn (Zea mays L., var. Silver Queen) was monitored during early and late stages of growth in separate plots of the same field. The radiation sensors were mounted on automated reversing carriages which were mounted either at 25 or at $300 \mathrm{~cm}$ above ground level. The mounted sensors traversed a $3.3 \mathrm{~m}$ span to achieve spatial averaging. Output voltages of each radiation sensor was continuously integrated and recorded at hourly intervals. Early and late plant water stresses were induced by inadequate rainfall and the use of automatic rainfall shelters, respectively. Plant height and leaf area were measured in a plant population of 67750 plant ha $^{-1}$. Early drought delayed canopy development while in the late drought treatment the canopy was nearly developed before late drought was imposed. When nonstressed plants were fully developed, net radiation $25 \mathrm{~cm}$ above the soil surface was $32 \%$ of the above-canopy net radiation. As leaves wilted during early drought, net radiation, at $25 \mathrm{~cm}$ above the soil surface, increased from 32 to $46 \%$ of that measured above the canopy and increased to $51 \%$ due to late drought. The observed net radiation differences were induced by imposed plant water stresses which also had the effect of reducing fresh ear yield by 25 to $45 \%$ of the irrigated yield for early and late-stressed treatments, respectively.

\section{INTRODUCTION}

Because radiation is the most important energy component of the microclimate, several investigators have studied the energy balance over and within corn canopies (Denmead et al., 1962; Allen et al., 1964; Allen and Brown, 1965; Stanhill et al., 1968). Tanner et al. (1960) measured net radiation above four plant population-geometry combinations. They found that net radiation measured over the 54000 plant ha ${ }^{-1}$ population was about $5 \%$ less than that over the 23000 plant ha ${ }^{-1}$ population and that there was little difference in net radiation among different planting configurations of the 32000 plant ha ${ }^{-1}$ population.

Aubertin and Peters (1961) used a net radiometer exposed $0.6 \mathrm{~m}$ above the canopy and found that net radiation above rows spaced $51 \mathrm{~cm}$ apart was about $4 \%$ less than that above rows spaced $102 \mathrm{~cm}$ apart for plant densities of 38000 and 77000 plant $^{-1} \mathrm{a}^{-1}$. Net radiation was the same over both populations in the $51 \mathrm{~cm}$ rows, but in $102 \mathrm{~cm}$ rows, radiation was $5 \%$ lower over the 77000 plant ha $^{-1}$ than the 38000 plant ha $^{-1}$ populations. 
Yao and Shaw (1964) measured net radiation above two plant populations where soil water was $60 \%$ of available soil water. They found net radiation over a 70000 population lower than over a 35000 plant ha $^{-1}$ population, with a difference of about 5\% at noon. The wider spacing and lower populations permitted more radiation to penetrate through the canopy to the soil surface than did the more narrow spacing and the higher populations.

Differences in net radiation measured within the same population at permanent and temporary mast locations were generally larger than those between the permanent mast locations in 42000 and 62000 plant ha $^{-1}$ populations (Linville and Dale, 1975). They concluded that the corn population densities in this range had little effect on the net radiation measured above the corn canopies, and resulted in insignificant yield and water use differences.

In this study net radiation was measured above and within a corn canopy in relation to plant water stress. As corn leaf water stress increased, light penetration into the canopy was evaluated in relation to net radiation within the canopy. The ratio of net radiation $25 \mathrm{~cm}$ above the soil surface to that $300 \mathrm{~cm}$ above it over the canopy was used as an index of in-canopy net radiation. Leaf area index $(L A I)$ was measured and correlated with the radiation measurements. Fresh ear yields were determined for early, and late plant water stress, and irrigated (nonstressed) sweet corn.

\section{METHODS AND MATERIALS}

Sweet corn (Zea mays L., var. Silver Queen) was grown on a Varina sandy loam (Plinthic Paleudult) near Florence, SC. The corn was planted on April 251973 (Julian day 249) in $102 \mathrm{~cm}$ rows. After emergence the corn seedlings were thinned to a population of 67750 plant ha $^{-1}$. Cultural practices and the experimental layout have been described by Reicosky et al. (1976).

Three levels of seasonal plant water stress were imposed on the corn crop and are referred to as unstressed (water applied in $2.5 \mathrm{~cm}$ increments when tensiometers at the $30 \mathrm{~cm}$ depth read $-0.2 \mathrm{~b}$ ), early stressed due to inadequate rainfall (irrigated after June 19), and late stressed with automated shelters (irrigated early and sheltered from rainfall after June 19).

Net radiation near the soil surface and above the plant canopy was measured with Fritschen-type net radiometers (1963). The net radiometers were inflated with dry air from a small pressure-regulated $\left(30 \mathrm{~cm} \mathrm{H}_{2} \mathrm{O}\right)$ air pump. The net radiometers were mounted on level reversible carriages that actually transported the sensor back and forth over a $3.3 \mathrm{~m}$ length of row in 40 minutes $(16.5 \mathrm{~cm} / \mathrm{min}$.) (Fig. 1). This array was used to measure net radiation $25 \mathrm{~cm}$ above the ground parallel to the row midway between planted rows. For above-plant canopy measurements, the net radiometer carriage was mounted $300 \mathrm{~cm}$ above ground level and placed diagonally across four corn rows to give spatial averaging. Net radiometer output voltages were continuously integrated, recorded on storage counters, and read-out hourly by a 


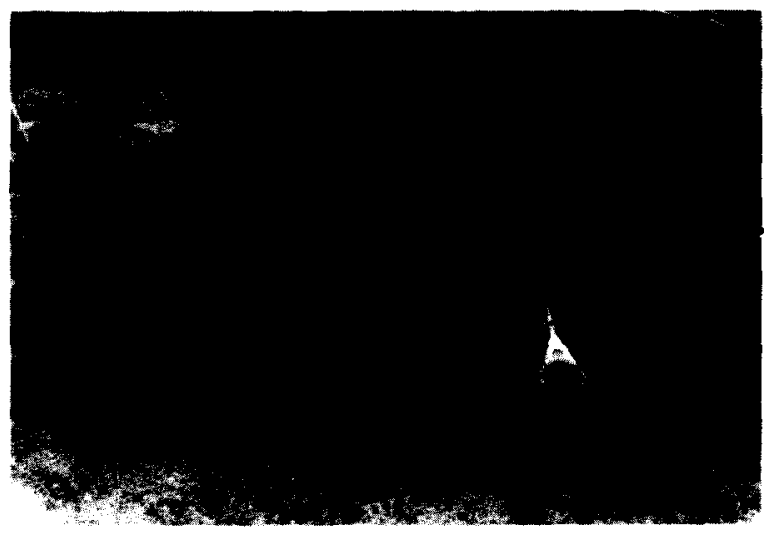

Fig. 1. Net radiometer and the traversing system for measuring net radiation $25 \mathrm{~cm}$ above the ground.

programmed data acquisition system. All net radiation values reported are hourly or daily (daylight hours only) integrated values.

Plant height was measured from the top of a $5 \times 5 \times 15-\mathrm{cm}$ wooden hub stake driven flush with the soil surface to the tip of the tassel after its appearance. $L A I$ was determined from eight plants in each treatment at 7 to 10-day intervals. Leaf area was calculated as the product of the leaf length and the average leaf width of 32 plants. The average leaf width was taken as $75 \%$ of the maximum leaf width.

\section{RESULTS AND DISCUSSION}

Plant height (Fig. 2) increased slowly in the early stages of growth and then increased rapidly 45 days after emergence (June 19,1973$)$. Corn plants reached their maximum height 55 days after emergence. A significant difference in height between the early-stressed and unstressed treatments was apparent 32 days after emergence (June 7) during the peak of early drought.

Differences in $L A I$ between the early and unstressed treatment were more pronounced than plant height (Fig. 3). Both early-stressed and unstressed treatments had essentially the same $L A I$ until 35 days after emergence when plant water stress symptoms became apparent. At this stage, differences in $L A I$ between the early-stressed and unstressed treatments were distinctly different. Both treatments reached the maximum $L A I$ prior to tasseling. After tasseling, $L A I$ of both the early-stressed and unstressed treatments decreased slightly as a few of the lower leaves dropped from the plants. But the $L A I$ of the unstressed treatment decreased at a lower rate because of a greater leaf drop due to water stress for the early-stressed treatment.

The ratio of the net radiation at $25 \mathrm{~cm}$ to that measured at $300 \mathrm{~cm}$ above ground level was near unity for $L A \Gamma$ 's less than one (Fig. 4). However, as the $L A I$ increased in both unstressed and early-stressed treatments, this ratio 


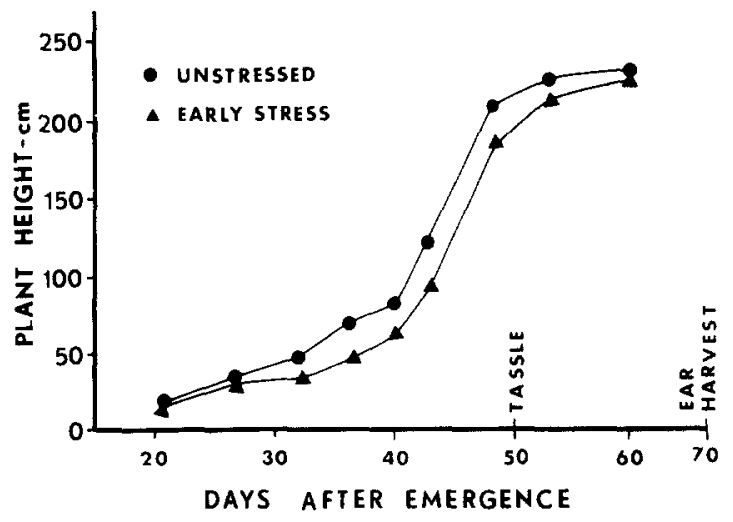

Fig. 2. Plant height at various stages of growth for early-stressed and unstressed plants.

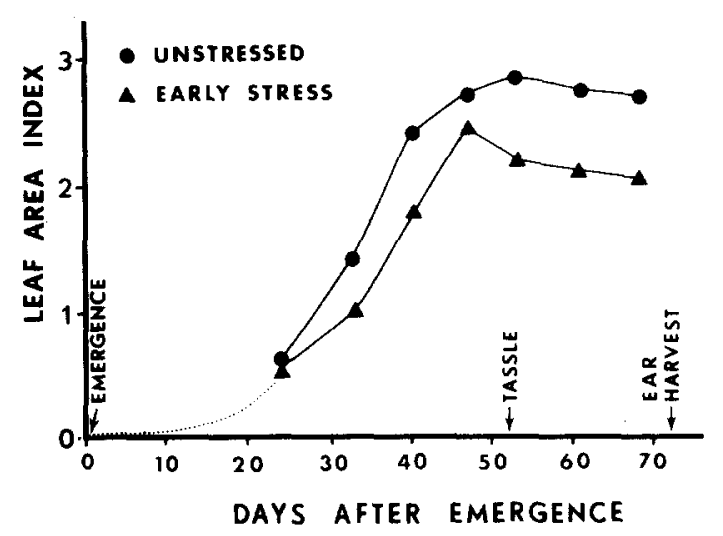

Fig. 3. Leaf area index as a function of time for early-stressed and unstressed plants.

geometrically decreased to a minimum of 0.3 for $L A I$. These data indicate that as the crop achieved $L A I$ equal to 3 at its maximum height, the net radiation $25 \mathrm{~cm}$ above the surface was $1 / 3$ of that above the canopy in the irrigated (unstressed) treatment. The maximum $L A I$ in the early-stressed corn was about 2.5 .

Hourly values of net radiation plotted as a function of time for selected days show the gradual changes in above- to in-canopy radiation in relation to plant water stress (Figs. 5 and 6 ). The above-canopy net radiation on unstressed plants was higher than that on the early-stressed plants on June 18 and 28. However, net radiation in the canopy on June 18 was relatively high in both the unstressed and early-stressed plants, reflecting considerable openness of the canopy at this stage of growth ( $L A I$ about 2). Net radiation measured within the canopy progressively decreased as the canopy developed until first ear harvest on July 16. 


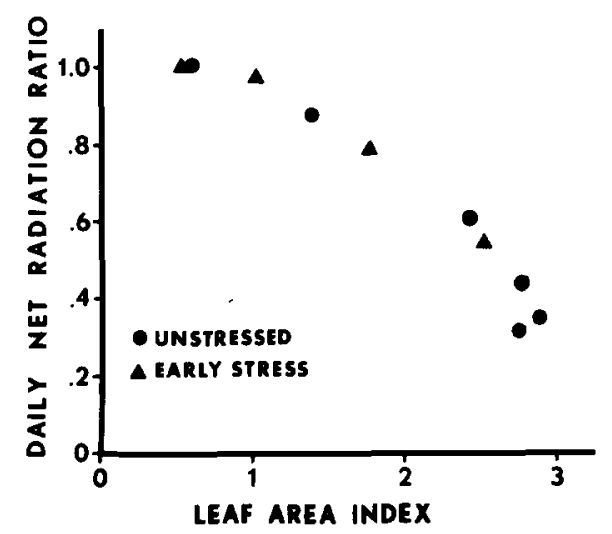

Fig. 4. The ratio of the net radiation within the canopy to that above the canopy in relation to leaf area index.

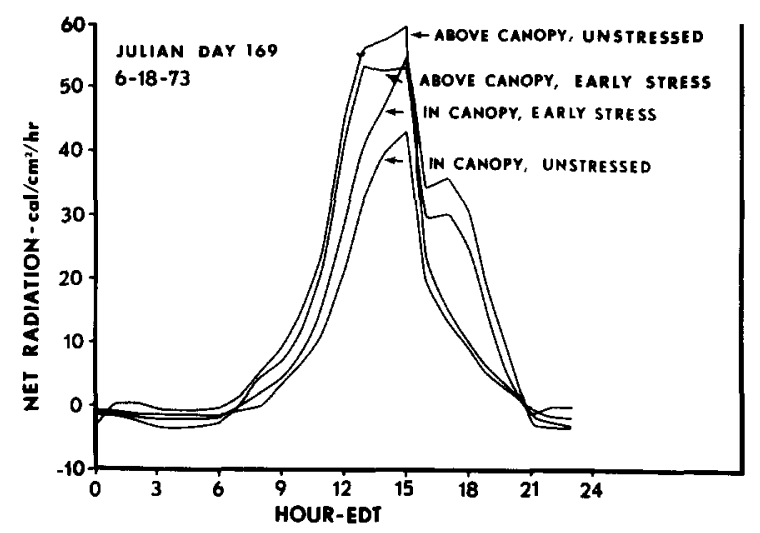

Fig. 5. The net radiation above and within the canopy for early-stressed and unstressed plants, June 18, 1973.

Hourly late stress effects on net radiation in and above the canopy after 23 days without rainfall are given in Fig. 7 for July 12. Automated rain shelters had excluded rainfall since June 19. The ratio was 0.52 for July 12,67 days after emergence, which was a typical day in the late stress period.

Data presented in Fig. 8 represent the ratio of the daily net radiation measured at $25 \mathrm{~cm}$ and to that at $300 \mathrm{~cm}$ above the ground level in relation to induced plant water stresses in the 1973 growing season. The net radiation ratio gradually decreased as the corn canopy developed in both the unstressed and the early stressed treatments. The ratio for the unstressed treatment began to decrease about seven days earlier than the decrease for the earlystressed treatment. When the corn reached its maximum height $(L A I=3)$, net radiation at the $25 \mathrm{~cm}$ level was approximately $32 \%$ of that above the 


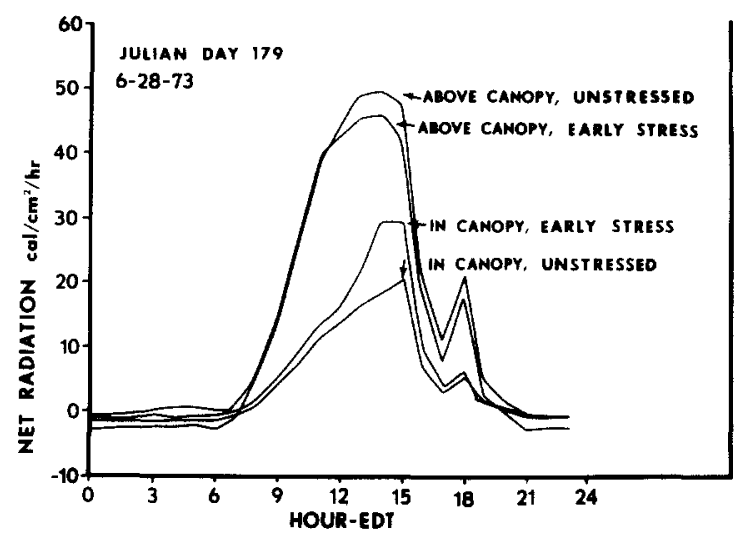

Fig. 6. Net radiation above and within the canopy for both early-stressed and unstressed plants, June $28,1973$.

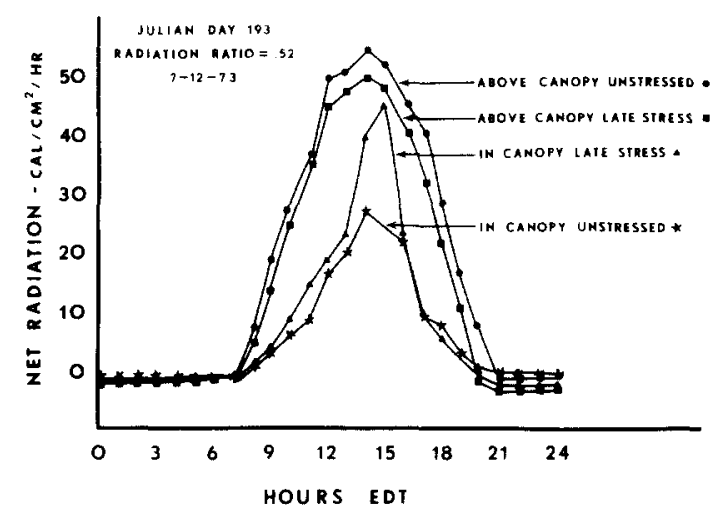

Fig. 7. Net radiation above and within the canopy for both late-stressed and unstressed plants near maturity, July 12, 1973.

canopy under irrigation. The radiation ratio for the early-stressed treatment reached its maximum value of $45 \% 55$ days after emergence. The difference can be explained in part by delayed $L A I$ development and by curling of leaves, both of which permitted greater ground level light penetration for the earlystressed treatment. Since the soil surfaces of both the early-stressed and unstressed plots were dry, the greater net radiation near the ground in the early-stressed plot would have the effect of imparting additional heat to the soil and the air near the ground.

The effect of late-season drought on daily net radiation near maturity was pronounced (Fig. 8). The net radiation was assumed to be essentially the same as that of the unstressed treatment until late stress was imposed, even though no measurements were made because the treatments had the same water history until the late-stress treatment was imposed. Integrated net radi- 


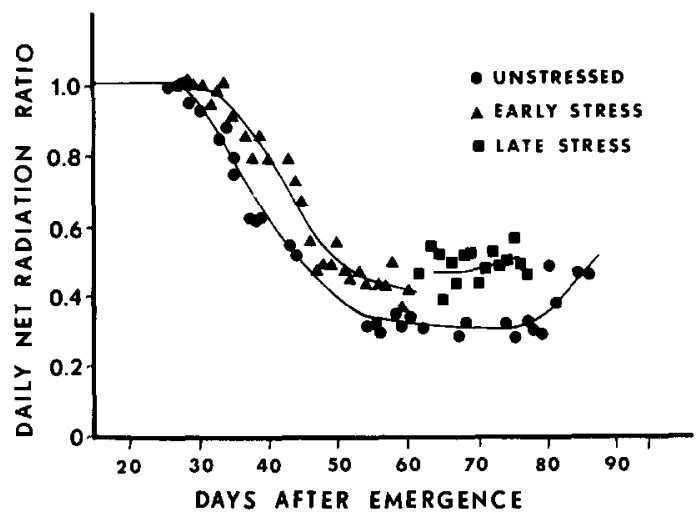

Fig. 8. The ratio of the net radiation measured at $25 \mathrm{~cm}$ to that measured at $300 \mathrm{~cm}$ as a function of time during the 1973 growing season, showing the effect of drought on early and late plant water stress, and on unstressed plants.

ation for the late stressed plots had an average ratio of the net radiation in the canopy to that above the canopy of 0.51 , compared to unstressed plants which showed $32 \%$ of the net radiation at $25 \mathrm{~cm}$ above the soil surface. After July 24, the ratio increased quite sharply as the plants matured, because ears were harvested. This increase in the ratio of net radiation was partially associated with a decrease in the effective $L A I$. The increase in net radiation at the $25 \mathrm{~cm}$ level was also enhanced by earlier senescence of lower leaves than of the upper leaves as the plant approached maturity.

The significant decrease in the ratios of net radiation measured at $25 \mathrm{~cm}$ above the ground in the corn canopy for the three stages of water stress was associated with, but not the cause of, decreased marketable ear yield and total dry matter at the end of the season. Marketable corn ear yield was 10.1, 13.8, and 18.3 tha ${ }^{-1}$ for late-stressed, early-stressed and nonstressed plants, respectively (Table I). Differences between these mean yields were statistically different at the $P \geqslant 0.05$ level. A yield decrease of $25 \%$ corre-

\section{TABLE I}

Marketable fresh ear yields and net radiation ratios for nonstressed, early-stressed, and late-stressed plants

\begin{tabular}{llllc}
\hline Plant stress treatment & $\begin{array}{l}\text { Fresh ear yield } \\
\left(\mathrm{t} \mathrm{ha}^{-1}\right)\end{array}$ & $\begin{array}{l}\text { Yield decrease } \\
(\%)\end{array}$ & \multicolumn{2}{c}{ Radiation ratio } \\
\hline Unstressed & $18.3^{*}$ & - & 32 & $\%$ \\
Early stressed & 13.8 & 25 & 46 & -44 \\
Late stressed & 10.1 & 45 & 51 & -59 \\
\hline
\end{tabular}

* Yields differ significantly at $P \geqslant 0.05$. 
sponded to a radiation ratio difference of $14 \%$ between the nonstressed and late-stressed plants. Total dry matter at the end of the growing season decreased $25 \%$ due to the effects of the late-season stress.

\section{ACKNOWLEDGMENT}

This research was carried out in cooperation with the South Carolina Agricultural Experiment Station.

\section{REFERENCES}

Allen, L.H., Yocum, C.S. and Lemon, E.R., 1964. Photosynthesis under field conditions. VII. Radiant energy exchanges within a corn crop canopy and implications in water use efficiency. Agron. J., 56: 253-259.

Allen, L.J., Jr. and Brown, K.W., 1965. Shortwave radiation in a corn crop. Agron. J., 57: 575-580.

Aubertin, G.M. and Peters, D.B., 1961. Net radiation determinations in a cornfield. Agron. J., 53: 269-272.

Denmead, O.T., Fritschen, L.J. and Shaw, R.H., 1962. Spatial distribution of net radiation in a corn field. Agron. J., 54: 505-510.

Fritschen, L.J., 1963. Construction and evaluation of a miniature net radiometer. J. Appl. Meteorol., 2: 165-172.

Linvill, D.F. and Dale, R.F., 1975. Population density and sampling location effects on net radiation measurements over corn. Agron. J., 67: 463-468.

Reicosky, D.C., Campbell, R.B. and Doty, C.W., 1976. Corn plant water stress as influenced by chiseling, irrigation and water table depth. Agron. J., 68: 499-503.

Stanhill, G., Cox, J.T. and Moreshet, S., 1968. The effect of crop and climatic factors on the radiation balance of an irrigated maize crop. J. Appl. Ecol., 5: 707-720.

Tanner, C.B., Peterson, A.E. and Love, J.R., 1960. Radiant energy exchange in a cornfield. Agron. J., 52: 373-379.

Yao, A.Y.M. and Shaw, R.H., 1964. Effect of plant population and planting pattern of corn on the distribution of net radiation. Agron. J., 56: 165-169. 